\title{
直接硼氢化物燃料电池(DBFC)阳极催化剂的研究进展
}

\author{
田 晓，段如霞，赵丽娟，那仁格日乐
}

(内蒙古师范大学 物理与电子信息学院, 功能材料物理与化学自治区重点实验室, 呼和浩特 010022)

\begin{abstract}
摘 要: 直接硼氢化物燃料电池(DBFC)具有理论电池电压高和能量密度大等特点, 而其阳极催化剂是决定电池性 能的关键因素之一。因此, 研究者们在提高阳极催化剂催化活性和降低催化剂成本方面开展了大量的研究工作。本 文在简要介绍 DBFC 工作原理和阳极反应机理的基础上，从催化剂种类和性能角度综述了近年来 DBFC 中贵金属、 过渡金属以及储氢合金阳极催化剂的主要研究进展，指出了阳极催化剂研究所面临的问题，同时提出了今后的发 展方向。
\end{abstract}

关 键 词: 直接硼氢化物燃料电池; 阳极催化剂; 催化活性; 水解反应

中图分类号: TM911 文献标识码: A

\section{Anode Catalyst for the Direct Borohydride Fuel Cell}

\author{
TIAN Xiao, DUAN Ru-Xia, ZHAO Li-Juan, NAREN Ge-Ri-Le
}

\begin{abstract}
(Inner Mongolia Key Laboratory for Physics and Chemistry of Functional Materials, School of Physics and Electronic Information, Inner Mongolia Normal University, Hohhot 010022, China)
\end{abstract}

\begin{abstract}
Direct borohydride fuel cell (DBFC) is currently attracted attentions due to its high theoretical cell voltage and power density. However, the anode catalyst of this type of battery is one of the key factors that decide the battery performance. A lot of researches have been done to improve catalytic activity and decrease the cost of the anode catalysts for DBFC in recent years. On the basis of the work principle and anode reaction mechanism of DBFC, the recent progresses of precious metal, transition metal and hydrogen storage alloy as anode catalyst for DBFC are reviewed according to perspective of catalytic performance and types. The existing problems of the anode catalyst is pointed out and the developments of the anode catalyst for DBFC are also proposed.
\end{abstract}

Key words: direct borohydride fuel cell; anode catalyst; catalytic activity; hydrolysis reaction

化石能源的消耗会引起严重的环境污染，为兼 顾能源利用、环境保护和人类可持续发展, 研究能 够取代化石能源的清洁新能源和新能源技术是全人 类亟待解决的紧迫课题。氢能源作为一种储量丰富、 来源广泛、能量密度高的清洁能源, 引起了广泛关 注 ${ }^{[1-2]}$ 。燃料电池是通过电化学反应直接将储存在燃 料中的化学能转化为电能的装置, 因其具有能量转
换效率高、能量密度大、环境污染小、噪音低、性 能可靠和使用时间长等优点, 而成为人们积极研发 的新能源技术 ${ }^{[3-4]}$ 。我国国务院出台的《国家中长期 科学与技术发展规划纲要》中已明确提出发展氢能 和燃料电池技术，这也受到许多发达国家的高度重 视，成为未来具有发展潜力的新能源和能源技术。

直接嗍氢化物燃料电池 (Direct Borohydride

收稿日期: 2017-02-08; 收到修改稿日期：2017-04-17

基金项目: 内蒙古自治区高等学校科学技术研究项目(NJZZ17040); 内蒙古自治区人才开发基金; 内蒙古自然科学基金 (2014MS0542); 国家自然科学基金(51661027, 21663018)

Inner Mongolia Autonomous Region Higher Education Science and Technology Research Foundation (NJZZ17040); Inner Mongolia Autonomous Region Talent Development Foundation ; Inner Mongolia Autonomous Region Natural Science Foundation (2014MS0542); National Natural Science Foundation of China (51661027, 21663018)

作者简介: 田 晓(1972-), 女, 教授. E-mail: nsdtx@126.com 
Fuel Cell, DBFC)是一种将存储在硼氢化物 $\mathrm{BH}_{4}{ }^{-}$中 的化学能在阳极催化剂作用下直接转化为电能的新 型燃料电池。嗍氢化物是一类含氢量很高的化合物 (例如, $\mathrm{NaBH}_{4}$ 含氢量为 $10.6 \mathrm{wt} \%$ ), 嗍氢化物化学能 的利用实质也是氢能的利用。可见, $\mathrm{DBFC}$ 是将氢能 和燃料电池结合到一起的一种新能源技术, 也是一 种低温(工作温度低于 $100^{\circ} \mathrm{C}$ ) 燃料电池。与其他低温 燃料电池 (质子交换膜燃料电池 (PEMFC) 和直接甲 醇燃料电池(DMFC)) 相比, DBFC 具有更高的输出 电压和功率密度、可以用普通的催化剂替代贵金属、 可在常温下工作、无毒、运输安全等优点 ${ }^{[5-6]}$ 。此外, 它还克服了氢能源利用过程中氢储存和运输的瓶颈 问题。表 1 列出了常见低温燃料电池的技术状态。

基于上述优点, 近年来 $\mathrm{DBFC}$ 受到研究者们的 极大青睐。然而, DBFC 的性能很大程度上取决于嗍 氢化物分子在阳极上发生的电化学反应, 而阳极上 的电化学反应又直接受阳极催化剂的控制。燃料电 池一般都是用贵金属做催化剂, 贵金属的价格昂贵 和资源稀缺成为限制燃料电池在实际中的应用。因 此, 研究和开发稳定性高、催化活性好的非贵金属 催化剂对推动燃料电池产业化发展具有重要的理论 和现实意义。

因此, 本文在简要介绍 DBFC 的工作原理和阳 极氧化反应机理的基础上, 从催化剂种类和性能角 度综述了近年来贵金属、过渡金属以及储氢合金作 为 DBFC 阳极催化剂研究取得的成果, 并展望了 DBFC 阳极催化剂的发展趋势。

\section{DBFC 工作原理及其阳极反应机理}

嗍氢化钠是 1942 年由美国的 Brown 等首次合 成, 20 世纪 60 年代 Indig 提出用 $\mathrm{NaBH}_{4}$ 作为燃料电 池燃料的设想，但在 2000 年之前有关 DBFC 的详细 研究还很少, 直到 2006 年才陆续有报道。近年来, DBFC 作为一种新型燃料电池, 由于具有理论电压 高、能量密度大、无污染、安全等优点, 而受到国
内外研究者的广泛关注。

DBFC 利用嗍氢化物的碱性溶液作为燃料、 $\mathrm{O}_{2} /$ 空气 $\mathrm{H}_{2} \mathrm{O}_{2}$ 为氧化剂, 在催化剂作用下发生氧化和 还原反应, 将 $\mathrm{BH}_{4}{ }^{-}$化学能在阳极催化剂作用下直接 转化为电能的装置。图 1 是 DBFC 的工作原理示意 图 $^{[4]}$, 其相应的电极和电池反应方程式如下:

$$
\begin{gathered}
\text { 阳极反应: } \mathrm{BH}_{4}^{-}+8 \mathrm{OH}^{-} \rightarrow \mathrm{BO}_{2}{ }^{-}+6 \mathrm{H}_{2} \mathrm{O}+8 \mathrm{e}^{-} \\
\left(E_{\mathrm{a}}^{\mathrm{o}}=-1.24 \mathrm{~V} \text { vs. SHE }\right) \\
\text { 阴极反应: } 2 \mathrm{O}_{2}+4 \mathrm{H}_{2} \mathrm{O}+8 \mathrm{e}^{-} \rightarrow 8 \mathrm{OH}^{-} \\
\left(E_{\mathrm{c}}^{\mathrm{o}}=0.4 \mathrm{~V} \text { vs. } \mathrm{SHE}\right) \\
\text { 电池反应: } \\
\mathrm{BH}_{4}{ }^{-}+2 \mathrm{O}_{2} \rightarrow \mathrm{BO}_{2}{ }^{-}+2 \mathrm{H}_{2} \mathrm{O} \\
\left(E^{\mathrm{o}}=1.64 \mathrm{~V}\right)
\end{gathered}
$$

由反应方程可知, 理论上 $\mathrm{DBFC}$ 中每个 $\mathrm{BH}_{4}{ }^{-}$在 阳极发生电化学氧化反应释放出 8 个电子后被完全 氧化为 $\mathrm{BO}_{2}^{-}$。但在实际的 $\mathrm{DBFC}$ 中, 放出的电子数 往往低于 8 , 从而使燃料的利用率下降, 这主要是由 于 $\mathrm{BH}_{4}{ }^{-}$在阳极催化剂作用下发生氧化反应的同时或 随后还会发生水解反应，释放出氢气。水解反应方 程式如下:

水解反应: $\mathrm{BH}_{4}{ }^{-}+2 \mathrm{H}_{2} \mathrm{O} \rightarrow \mathrm{BO}_{2}{ }^{-}+4 \mathrm{H}_{2}$

将反应方程(1)和(4)相加, 得到的就是实际阳 极发生的反应，即：

$$
\mathrm{BH}_{4}{ }^{-}+x \mathrm{OH}^{-} \rightarrow \mathrm{BO}_{2}{ }^{-}+(x-2) \mathrm{H}_{2} \mathrm{O}+(4-x) \mathrm{H}_{2}+x \mathrm{e}^{-}
$$

式中 $x$ 代表每个 $\mathrm{BH}_{4}{ }^{-}$在阳极发生电化学氧化反应释 放出的电子数。释放电子数的多少与阳极催化剂直 接相关。

阳极催化剂是影响 $\mathrm{BH}_{4}{ }^{-}$电化学氧化反应和水 解反应的关键因素。一般来说, 贵金属催化剂对电 化学氧化反应和水解反应同时具有良好的催化活性, 但是昂贵的成本限制了其大范围的使用。此外，水 解反应既导致燃料利用率下降，产生的氢气又会造 成电池的安全隐患。在 DBFC 中, 嗍氢化物中 $\mathrm{BH}_{4}^{-}$

\begin{tabular}{|c|c|c|c|c|c|c|}
\hline Type & Electrocatalyst & Fuel & Oxidant & $\begin{array}{l}\text { Theoretical data of } \\
\text { open circuit voltage }\end{array}$ & Main existence question & $\begin{array}{l}\text { Possible application } \\
\text { fields }\end{array}$ \\
\hline PEMFC & $\mathrm{Pt}$ & $\begin{array}{c}\mathrm{H}_{2} / \text { Reformer } \\
\text { hydrogen }\end{array}$ & $\begin{array}{c}\text { Air/Pure } \\
\text { oxygen }\end{array}$ & $1.23 \mathrm{~V}$ & $\begin{array}{l}\text { Hydrogen supply } \\
\text { system, catalyst cost }\end{array}$ & $\begin{array}{l}\text { Hybrid electric } \\
\text { vehicles, portable } \\
\text { power source }\end{array}$ \\
\hline DMFC & $\mathrm{Pt}, \mathrm{Pt}-\mathrm{Ru}$ & Methanol & Air & $1.183 \mathrm{~V}$ & $\begin{array}{l}\text { Catalyst poisoning, } \\
\text { catalyst cost }\end{array}$ & $\begin{array}{l}\text { A small mobile } \\
\text { power source }\end{array}$ \\
\hline DBFC & $\begin{array}{l}\text { Non-noble } \\
\text { metal }\end{array}$ & Borohydride & $\begin{array}{c}\mathrm{Air} / \mathrm{O}_{2} / \\
\mathrm{H}_{2} \mathrm{O}_{2}\end{array}$ & $1.64 \mathrm{~V}$ & $\begin{array}{l}\text { Hydrolysis reaction, } \\
\text { catalyst cost }\end{array}$ & $\begin{array}{l}\text { Portable electronics, } \\
\text { mobile power }\end{array}$ \\
\hline
\end{tabular}
氧化释放的电子数以及反应过程中伴随的水解反应 都与阳极催化剂密切相关。阳极催化剂是决定 DBFC 性能的主要因素, 相关阳极催化剂的研究也 是目前 DBFC 研究领域的热点。寻找一种对嗍氢化

表 1 常见低温燃料电池的技术状态

Table 1 Technical state of common low temperature fuel cells 


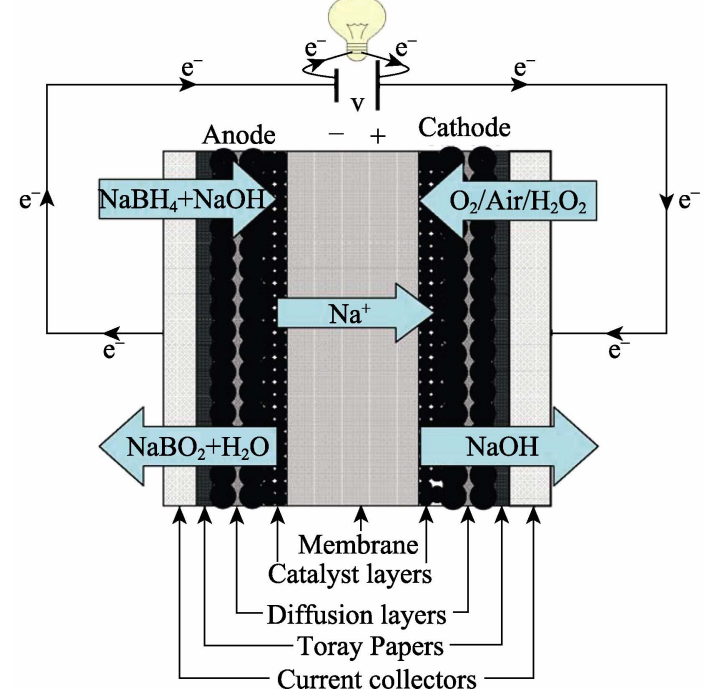

图 1 DBFC 工作原理示意图 ${ }^{[4]}$

Fig. 1 Schematic diagram of $\mathrm{DBFC}^{[4]}$

物直接氧化具有良好催化活性，而对其水解副反应 具有较低催化活性或可将水解反应中产生的氢转化 利用的非贵金属阳极催化剂是目前 DBFC 研究的重 点问题。

\section{DBFC 的阳极催化剂}

\section{1 贵金属催化剂}

贵金属不仅对电化学氧化反应有较好的催化活 性，而且对水解反应也有很好的催化性。因此, DBFC 使用贵金属作为阳极催化剂有很高的能量密度，但 法拉第效率却不够高 ${ }^{[4]}$ 。作为 DBFC 阳极催化剂的 贵金属主要有 $\mathrm{Pt} 、 \mathrm{Au} 、 \mathrm{Pd} 、 \mathrm{Ag}$ 以及 $\mathrm{Os}$ 等金属及其 合金。最初, 研究者们主要采用贵金属单质做阳极催 化剂。本课题组利用 Web of Science (SCI) 数据库, 对 2000 2016 年期间使用贵金属单质作为 DBFC 阳极 催化剂的文献进行了粗略的统计, 具体见图 2 所示。

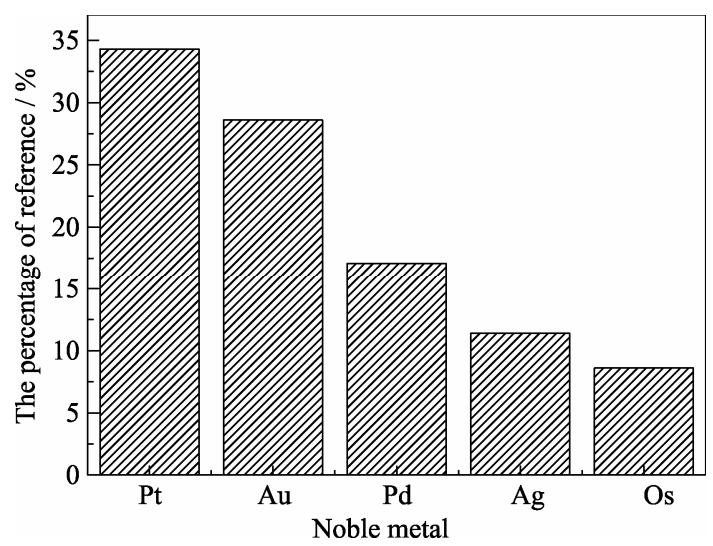

图 2 贵金属单质用作 DBFC 阳极催化剂研究文献所占比例 Fig. 2 Percentage of reference on variously noble metal as DBFC anode catalyst

According to the Web of Science (2000-2016)
图 2 表明, 各种贵金属作为 DBFC 阳极催化剂 的研究文献百分比是不同的, 研究文献排序: $\mathrm{Pt}>$ $\mathrm{Au}>\mathrm{Pd}>\mathrm{Ag}>\mathrm{Os}$ 。这反映了研究者对各种贵金属单质 的关注度，也在一定程度上说明各种贵金属在 DBFC 阳极催化剂中所起的作用是不同的。在这些 贵金属中, $\mathrm{Pt}$ 和 $\mathrm{Au}$ 作为 DBFC 阳极催化剂比其他金 属对嗍氢化物有更好的催化活性 ${ }^{[7-8]}$, 因此得到更 多关注。

依据阳极反应方程(1), $\mathrm{DBFC}$ 中每个 $\mathrm{BH}_{4}{ }^{-}$发生 电化学氧化反应可释放出 8 个电子。然而, 文献报道 仅在 $\mathrm{Au}$ 用作 $\mathrm{DBFC}$ 阳极催化剂时，放出 8 电子 ${ }^{[9-11]}$ 。 而 $\mathrm{Au}$ 电极通常表现出很慢的动力学性能, 因此输 出电流和功率都很小 ${ }^{[10-13]}$ 。从燃料电池输出功率角 度看, $\mathrm{Pt}$ 和 $\mathrm{Pd}$ 电极比 $\mathrm{Au}$ 电极更优越。文献[14-15] 研究表明, 尽管贵金属 $\mathrm{Ag}$ 对 $\mathrm{BH}_{4}{ }^{-}$的氧化反应也具 有比较优越的催化活性, 而且 $\mathrm{Ag}$ 对其水解反应无 催化作用, 非常适合作为 DBFC 阳极催化剂, 但 $\mathrm{Ag}$ 电极的动力学性能也非常缓慢, 输出功率低, 同时 价格昂贵, 因此不能单独使用作为阳极催化剂。 Chatenet 等 ${ }^{[9]}$ 也报道在 $\mathrm{BH}_{4}{ }^{-}$发生电化学氧化反应时, $\mathrm{Au}$ 和 $\mathrm{Ag}$ 大约可释放出近 $8 \mathrm{e}$, 而 $\mathrm{Pt}$ 仅能释放出 $4 \mathrm{e}$ 。 $\mathrm{Au}$ 和 $\mathrm{Ag}$ 表现出高效率主要是由于它们对 $\mathrm{BH}_{4}{ }^{-}$发生 的水解反应几乎没有催化性。但是, $\mathrm{Au}$ 和 $\mathrm{Ag}$ 的动 力学性能非常缓慢, $\mathrm{Au}$ 比 $\mathrm{Ag}$ 的动力学性能要好一 些。相比较而言, $\mathrm{Pt}$ 和 $\mathrm{Pd}$ 催化剂对 $\mathrm{BH}_{4}$ 发生的电化 学氧化反应和水解反应都有好的催化活性 ${ }^{[16-18]}$ 。因 而，使用这些金属作为催化剂具有很高的功率密度， 但库仑效率却很低。Celikkan 等 ${ }^{[12]}$ 对比了 $\mathrm{Au} 、 \mathrm{Pt}$ 、 $\mathrm{Ag} 、 \mathrm{Pd}$ 和 $\mathrm{Ni}$ 对 $\mathrm{BH}_{4}{ }^{-}$电化学氧化反应的催化活性, 发现所有合金中 $\mathrm{Au}$ 的催化活性最佳，而 $\mathrm{Ni}$ 最差。 Cheng 等 ${ }^{[19]}$ 也对比研究了 $\mathrm{Pt} / \mathrm{C} 、 \mathrm{Au} / \mathrm{C} 、 \mathrm{Ag} / \mathrm{C} 、 \mathrm{Pd} / \mathrm{C}$ 和 $\mathrm{Ni} / \mathrm{C}$ 作为阳极催化剂 DBFC 的性能, 发现 DBFC 的开路电压 $(\mathrm{OCV})$ 值的顺序是: $\mathrm{Ag} / \mathrm{C}>\mathrm{Ni} / \mathrm{C}>\mathrm{Pt} / \mathrm{C}>$ $\mathrm{Au} / \mathrm{C}>\mathrm{Pd} / \mathrm{C}$, 而 $\mathrm{DBFC}$ 的最大功率密度值的顺序是: $\mathrm{Pd} / \mathrm{C}>\mathrm{Au} / \mathrm{C}>\mathrm{Pt} / \mathrm{C}>\mathrm{Ag} / \mathrm{C}>\mathrm{Ni} / \mathrm{C}$ 。也有人将贵金属 Os 用作 DBFC 的阳极催化剂 ${ }^{[20]}$, 研究发现 Os 对 $\mathrm{BH}_{4}{ }^{-}$电化学氧化反应也具有一定催化活性, 用 Os 作为阳极催化剂的 $\mathrm{DBFC}$ 的功率密度在 $60^{\circ} \mathrm{C}$ 时达到 $109 \mathrm{~mW} / \mathrm{cm}^{2}$ 。

由于催化作用是发生在电极表面的一种化学反 应, 催化剂需要尽可能大的比表面积。Liu 等 ${ }^{[21]}$ 对比 研究了多孔纳米碳载 Pt 和普通碳载 Pt 催化剂的性 能, 研究表明多孔纳米碳载 Pt 催化剂具有更高的电 流密度和更大的功率密度。同理, Reza 等 ${ }^{[22]}$ 对比研 究了石墨烯载 $\mathrm{Pt}$ 纳米颗粒催化剂和石墨载 $\mathrm{Pt}$ 纳米 颗粒催化剂的性能, 发现石墨烯载 Pt 纳米颗粒催化 
剂对嗍氢化物具有更好的导电性和电催化活性。最 近, Martins 等 ${ }^{[23]}$ 对比了 Pd 纳米颗粒分散在商业化 活性炭(Vulcan XC72)和两种生物基活性炭(葡萄茎 活性炭 GSAC 和葡萄藤枝活性炭 VSAC) 上发生的电 化学氧化反应, 研究发现两种 $\mathrm{Pd} /$ 生物基活性炭的 电催化活性明显优于 $\mathrm{Pd}$ /商业活性炭。同时, 催化剂 颗粒越小、越容易分散在电极表面, 也能更有效改 善其催化作用。文献[24]报道纳米尺度催化剂的性 能要好于相应块体材料催化剂。

可见，任何一种贵金属单质催化剂都有优缺点。 到目前还未找到一种贵金属单质催化剂既对 $\mathrm{BH}_{4}{ }^{-}$电 化学氧化反应具有良好的催化活性, 又能抑制水解 反应。此外, 贵金属单质作为阳极催化剂时, 还需考 虑贵金属的晶体结构、担载基底等, 需要进行多方 面的研究。目前贵金属单质催化剂的研究相对较多, 相应的催化机理也比较清晰。

研究表明，二元合金催化剂的催化性能往往优 于一元金属单质催化剂 ${ }^{[25]}$ 。为改善贵金属单质作为 阳极催化剂的性能，制备一种既具有高催化活性又 具有高库仑效率的催化剂, 研究者们将贵金属与贵 金属、贵金属与非贵金属复合制备二元合金用作催 化剂。本部分仅综述前者, 后者将在后文中讨论。 目前研究发现，在贵金属与贵金属构成的二元合金 中有 $\mathrm{Au}-\mathrm{Pt}^{[18,25-26]} 、 \mathrm{Au}-\mathrm{Pd}^{[11,27]} 、 \mathrm{Pt}-\mathrm{Ru}^{[28]} 、 \mathrm{Pd}-\mathrm{Ir}^{[29]}$ 、 $\mathrm{Au}-\mathrm{Pd}^{[30]} 、 \mathrm{Pd}-\mathrm{Ag}^{[31]}$ 等。表 2 列出了具有代表性的 一些二元贵金属作为阳极催化剂的 DBFC 的性能 参数。
由表 2 可见，二元贵金属作为 DBFC 的阳极催 化剂时, 电池的功率密度往往介于两种贵金属单质 做催化剂的性能之间, 或者比贵金属单质的性能要 好。但二元贵金属催化剂的性能也随着两种贵金属 组元比例、制备方法以及担载基底的变化而变化。 例如, Lee 等 ${ }^{[27]}$ 为了减少 DBFC 中嗍氢化物的水解 反应使 DBFC 获得更好的性能，制备了不同质量比 $(1: 3 、 2: 2 、 3: 1)$ 的 Au-Pd 二元金属作为 DBFC 阳 极催化剂, 研究发现, 随着 Pd 含量的增加, 三种催 化剂对应的 DBFC 的电池的性能(电压和功率密度) 不断增加, 而析氢速率几乎相似。表明 $\mathrm{Au}-\mathrm{Pd}$ 二元 金属催化剂对 $\mathrm{BH}_{4}{ }^{-}$的水解活性很低，这正是由于 $\mathrm{Au}$ 和 $\mathrm{Pd}$ 协同作用所致。Lee 等同时将已商业化的 $\mathrm{Pd}$ 和 $\mathrm{Au}$ 金属催化剂分别与 $\mathrm{Au}-\mathrm{Pd}$ 二元金属催化剂 电池性能和析氢速度进行了对比。研究发现, $\mathrm{Pd} / \mathrm{C}$ 作为阳极催化剂的 DBFC 有良好的电池性能, 但却 很容易水解。可见, 易水解是 $\mathrm{Pd} / \mathrm{C}$ 电极的最大缺点。 与 $\mathrm{Pd} / \mathrm{C}$ 相比, $\mathrm{Au} / \mathrm{C}$ 不易水解析氢, 但电池性能较差; $\mathrm{Au}-\mathrm{Pd} / \mathrm{C}$ 催化性能介于 $\mathrm{Pd} / \mathrm{C}$ 和 $\mathrm{Au} / \mathrm{C}$ 之间。同样, 王 宏等 ${ }^{[30]}$ 研究发现, $\mathrm{Au}-\mathrm{Pd} / \mathrm{C}$ 无论是催化活性还是电 池的性能都要优于 $\mathrm{Au} / \mathrm{C}$ 和 $\mathrm{Pd} / \mathrm{C}$ 的, 并且两种金属 配比不同, 其性能也有明显的差异。李健等 ${ }^{[31]}$ 对不 同原子比的 $\mathrm{Pd}-\mathrm{Ag} / \mathrm{C}$ 催化剂进行了研究, 发现掺杂 适量 $\mathrm{Ag}$ 不仅可以提高催化剂的催化活性, 而且使 得 $\mathrm{BH}_{4}{ }^{-}$电氧化反应过程中的转移电子数增加, 其中 $\mathrm{Pd}_{75}-\mathrm{Ag}_{25} / \mathrm{C}$ 的催化活性和转移电子数均为最高。 Balciunaite 等 ${ }^{[32]}$ 研究发现 $\mathrm{PtCoB} / \mathrm{Cu}$ 多元合金催化

表 2 二元贵金属作为阳极催化剂的 DBFC 的性能参数

Table 2 Performance data for DBFCs employing binary noble metal anodes

\begin{tabular}{|c|c|c|c|c|c|}
\hline Anode catalyst & Cathode catalyst & Oxidant & $T /{ }^{\circ} \mathrm{C}$ & Power density $/\left(\mathrm{mW} \cdot \mathrm{cm}^{-2}\right)$ & Ref. \\
\hline $\mathrm{Au}-\mathrm{Pt}$ & $\mathrm{MnO}_{2}$ & Air & 25 & 20.0 & [25] \\
\hline $\mathrm{Pt}_{3}-\mathrm{Au}_{2}$ & $\mathrm{Pt} / \mathrm{C}$ & Humidified $\mathrm{O}_{2}$ & 65 & 161.0 & [26] \\
\hline $\mathrm{Pt}_{1}-\mathrm{Au}_{1}$ & Pt-based & $\mathrm{O}_{2}$ & 60 & 47.0 & [18] \\
\hline $\mathrm{Au}_{1}-\mathrm{Pd}_{1}$ & Pt-based & $\mathrm{O}_{2}$ & 60 & 31.0 & [11] \\
\hline $\mathrm{Pd}$ & $\mathrm{Pt} / \mathrm{C}$ & Humidified $\mathrm{O}_{2}$ & NA & $\sim 185.0$ & [27] \\
\hline $\mathrm{Au}$ & $\mathrm{Pt} / \mathrm{C}$ & Humidified $\mathrm{O}_{2}$ & NA & $\sim 82.0$ & [27] \\
\hline $5 w t \% A u-15 w t \% P d$ & $\mathrm{Pt} / \mathrm{C}$ & Humidified $\mathrm{O}_{2}$ & NA & $\sim 120.0$ & [27] \\
\hline $10 w t \% A u-10 w t \% P d$ & $\mathrm{Pt} / \mathrm{C}$ & Humidified $\mathrm{O}_{2}$ & 50 & $\sim 90.0$ & [27] \\
\hline $15 w t \% A u-5 w t \% P d$ & $\mathrm{Pt} / \mathrm{C}$ & Humidified $\mathrm{O}_{2}$ & 50 & $\sim 75.0$ & [27] \\
\hline Pt black & Pt black & NA & 60 & 31.6 & [28] \\
\hline $\mathrm{Pt}_{1}-\mathrm{Ru}_{1}$ black & Pt black & NA & 60 & 35.1 & [28] \\
\hline $\mathrm{Au}$ & $\mathrm{Au} / \mathrm{C}$ & NA & 20 & $\sim 28.0$ & [30] \\
\hline $\mathrm{Pd}$ & $\mathrm{Au} / \mathrm{C}$ & NA & 20 & $\sim 41.0$ & [30] \\
\hline $\mathrm{Au}_{2}-\mathrm{Pd}_{1}$ & $\mathrm{Au} / \mathrm{C}$ & NA & 20 & $\sim 46.0$ & [30] \\
\hline $\mathrm{Au}_{1}-\mathrm{Pd}_{1}$ & $\mathrm{Au} / \mathrm{C}$ & NA & 20 & $\sim 49.0$ & [30] \\
\hline $\mathrm{Au}_{1}-\mathrm{Pd}_{2}$ & $\mathrm{Au} / \mathrm{C}$ & NA & 20 & 56.8 & [30] \\
\hline
\end{tabular}

\footnotetext{
* NA: Information not available in the cited literature; * about number: The data from the figure cited literature
} 
剂对嗍氢化物的催化活性明显好于催化剂 Pt 和 $\mathrm{CoB} / \mathrm{Cu}$ 。可见, 在不考虑催化剂成本的基础上, 二 元甚至多元贵金属合金催化剂将是未来研究的一个 方向。

\section{2 过渡金属催化剂}

由于 DBFC 所用的燃料为硼氢化物碱溶液, 是 一种碱性电解质, 对催化剂的抗腐蚀性要求较低。 因此，除了贵金属外，较便宜的金属、合金及其化合 物也能用作 DBFC 的阳极催化剂。在非贵金属中, 过 渡金属作为 DBFC 阳极催化剂的研究占有一定比重。

为降低催化剂的成本, 人们对过渡金属 $\mathrm{Ni}$ 作 为阳极催化剂进行了较多研究。相对于贵金属, $\mathrm{Ni}$ 的催化活性较低, 且其电子转移数也不高(仅能达 到 4), 但可以得到一个较高的功率密度。由于 $\mathrm{BH}_{4}{ }^{-}$ 在 $\mathrm{Ni}$ 上的电催化反应为 $4 \mathrm{e}$ 反应, 实际的库仑效率 大约只有 $50 \%$, 燃料损失严重 ${ }^{[33]}$ 。 Liu 等 ${ }^{[17,34]}$ 用镍 粉作为阳极催化剂, $\mathrm{Pt} / \mathrm{C}$ 作为阴极催化剂装配单电 池, 在室温下获得 $40 \mathrm{~mW} / \mathrm{cm}^{2}$ 的最大功率密度。硼 氢化钠在阳极催化剂上的电催化反应为 $4 \mathrm{e}$, 库仑 效率近 $50 \%$ 。Celikkan 等 ${ }^{[12]}$ 对比了 $\mathrm{Au} 、 \mathrm{Pt} 、 \mathrm{Pd}$ 和 $\mathrm{Ni}$ 金属催化剂电极对 $\mathrm{BH}_{4}{ }^{-}$氧化反应的催化性能, 发现最具催化活性的金属是 $\mathrm{Au}, \mathrm{Pt}$ 和 Pd 也能表现 出较好的催化作用, 但金属 Ni 的催化活性却很差。 可见, 镍单独作为 DBFC 阳极催化剂的实际应用前 景不大。

双金属催化剂在催化活性和稳定性方面更优越 于单金属催化剂 ${ }^{[11,35]}$ 。为了改善单金属 $\mathrm{Ni}$ 催化剂的 性能, 研究者们对含 Ni 双金属催化剂 Ni-Pt、Ni-Au、 $\mathrm{Ni}-\mathrm{Ag}$ 以及 Ni-Pd 等进行了研究, 研究发现在许多氢 化反应中, 双金属催化剂比单金属 $\mathrm{Ni}$ 催化剂更稳定 而且催化活性更高 ${ }^{[35]}$ 。作为 DBFC 阳极催化剂, Gyenge 等 ${ }^{[18]}$ 研究发现 Ni-Pt/C(金属的摩尔比为 $\left.1: 1\right)$ 催化剂比 $\mathrm{Pt} / \mathrm{C}$ 催化剂的催化活性要好。同样, Jamard 等 ${ }^{[36]}$ 也对比了 $\mathrm{Ni}-\mathrm{Pt} / \mathrm{C}$ (金属的摩尔比为 $1: 1$ ) 和 $\mathrm{Pt} / \mathrm{C}$ 作为 DBFC 阳极催化剂的性能, 发现前者比后 者具有更高的库伦效率。考虑到 Ni-Pt 双金属催化剂 的催化性能与两种金属的成分比例密切相关, Geng 等 ${ }^{[37]}$ 对将不同质量的 $\mathrm{Pt}$ 添加到 $\mathrm{Ni} / \mathrm{C}$ 催化剂中制备 了一系列 Ni-Pt/C 双金属催化剂, 研究发现, 与 $\mathrm{Ni} / \mathrm{C}$ 催化剂相比, $\mathrm{Ni}_{37}-\mathrm{Pt}_{3} / \mathrm{C}$ (质量比, $\mathrm{Ni}: \mathrm{Pt}=37: 3$ ) 催化剂的电催化活性和稳定性得到明显的改善。在 其他条件相同情况下, 对比不同阳极催化剂 DBFC 的最大功率密度发现, $\mathrm{Ni}_{37}-\mathrm{Pt}_{3} / \mathrm{C}$ 阳极催化剂的 DBFC 的最大功率密度为最高(具体见图 3(a)所示)。此外, 添加 $\mathrm{Pt}$ 增大了 $\mathrm{DBFC}$ 的库伦效率, 但电池的效率仍 然不够令人满意。Duan 等 ${ }^{[38]}$ 和梁建伟等 ${ }^{[39]}$ 对合成
的一系列 $\mathrm{Ni}-\mathrm{Au} / \mathrm{C}$ 双金属催化剂研究发现, 与 $\mathrm{Au} / \mathrm{C}$ 催化剂相比, $\mathrm{Ni}_{1}-\mathrm{Au}_{1} / \mathrm{C}($ 摩尔比, $\mathrm{Ni}: \mathrm{Au}=1: 1$ )催化 剂的电催化活性最好。同样, 也对比了不同阳极催 化剂 DBFC 的最大功率密度, 具体见图 3(b) 所示。通 过对 $\mathrm{Ni}-\mathrm{Ag} / \mathrm{C}$ 双金属催化剂的研究 ${ }^{[40]}$ 发现, Ni-Ag/C 对 $\mathrm{NaBH}_{4}$ 氧化反应的动力学性能比 $\mathrm{Ag} / \mathrm{C}$ 快。 $\mathrm{Ni}_{1}$ $\mathrm{Ag}_{1} / \mathrm{C}$ (摩尔比, $\mathrm{Ni}: \mathrm{Ag}=1: 1$ ) 催化剂的最高电子转 移数是 4.8 。同样, 也对比了不同阳极催化剂 $\mathrm{DBFC}$ 的最大功率密度, 具体见图 3(c)所示。可见, 在 DBFC 中只有恰当比例的双金属催化剂才能更好的发挥作 用, 研究双金属组元比例也不容忽视。冯瑞香等 ${ }^{[41]}$ 通过机械球磨法也制备的 $\mathrm{Ag}-\mathrm{Ni}$ 双金属合金, 并将 其用作 DBFC 的阳极催化剂。研究表明, 这种双金 属催化剂为纳米粒子集聚的微米颗粒, 具有二元合 金的典型结构特征, 不仅能够催化嗍氢化物直接进 行电化学氧化, 而且可抑制硼氢化物的化学水解。 当采用 $\mathrm{Ag}-\mathrm{Ni} / \mathrm{C}$ 作为 $\mathrm{DBFC}$ 电池的阳极催化剂时, 对嗍氢化物燃料的利用率可达 $90 \%$ 以上。 Liu 等 ${ }^{[42]}$ 考虑到 $\mathrm{Ni}$ 有比较负的开放电路电势和较低的库伦 效率, 而 $\mathrm{Pd}$ 却正好与 $\mathrm{Ni}$ 相反, 因此将 $\mathrm{Ni}$ 粉和 $\mathrm{Pd}$ 粉按比例混合作为 DBFC 的阳极催化剂。测试结果 表明, Ni-Pd/C 双金属催化剂作为阳极催化剂的 $\mathrm{DBFC}$ 的最大功率密度明显大于 $\mathrm{Pd} / \mathrm{C}$ 和 $\mathrm{Ni} / \mathrm{C}$ 任一单 金属催化剂的最大功率密度, 具体见图 3(d)所示。

最近，也有人用稀土元素部分替代 $\mathrm{Ni}$ ，制备 $\mathrm{Ni}$ $\operatorname{Re}(\operatorname{Re}$ 代表稀土元素)二元金属作为 DBFC 的阳极催 化剂。Santos 等 ${ }^{[43]}$ 采用电弧熔炼法制备了 $\mathrm{Ni}-\mathrm{Ce}$ 合金 并用作 DBFC 的阳极催化剂, 研究发现尽管交换电子 数较低, 但 $\mathrm{DBFC}$ 的功率密度几乎与 $\mathrm{Pt}$ 用作阳极催 化剂时相似。随后，他们还制备了 Ni-Dy $\left(\mathrm{Ni}_{0.95} \mathrm{Dy}_{0.05}\right.$ 和 $\left.\mathrm{Ni}_{0.90} \mathrm{Dy}_{0.10}\right)$ 和 $\mathrm{Ni}-\mathrm{Sm}\left(\mathrm{Ni}_{0.95} \mathrm{Sm}_{0.05}\right.$ 和 $\left.\mathrm{Ni}_{0.90} \mathrm{Sm}_{0.10}\right)$ 二元合金并进行了研究。与 $\mathrm{Ni}$ 基和 $\mathrm{Pt}$ 基其他材料相 比, Ni-Re 合金的催化活性还是比较令人满意的。同 时发现 $\mathrm{Ni}_{0.95} \mathrm{Dy}_{0.05}$ 合金电极对硼氢化物的电催化活 性最高, 而 $\mathrm{Ni}_{0.90} \mathrm{Sm}_{0.10}$ 合金的电催化活性最低, $\mathrm{Ni}-\mathrm{Re}$ 合金转移的电子数大约是 $4 \mathrm{e}^{[44]}$ 。可见这类材料 作为 DBFC 阳极催化剂还是有可能的, 只是需要进 一步研究稀土的种类以及稀土与 $\mathrm{Ni}$ 的成分比例等。

此外，还有将 $\mathrm{Ni}$ 和其他过渡金属组合成二元合 金作为 DBFC 的阳极催化剂。例如, 文献[45]采用电 沉积法制备的 $\mathrm{Ni}-\mathrm{Cr}$ 二元合金作为 DBFC 的阳极催 化剂时, 嗍氢根的氧化电流是使用 $\mathrm{Ni}$ 单金属作阳极 催化剂时的二倍。分析认为, 催化活性的提高与 $\mathrm{Cr}$ 金属沉积在 $\mathrm{Ni}$ 金属表面有关, 并且 $\mathrm{Ni}-\mathrm{Cr}$ 二元合金 催化剂性能的改善还与沉积条件有关。最近, Zhiani 等 ${ }^{[46]}$ 合成了一种新的 DBFC 阳极催化剂是 Pd 修饰 

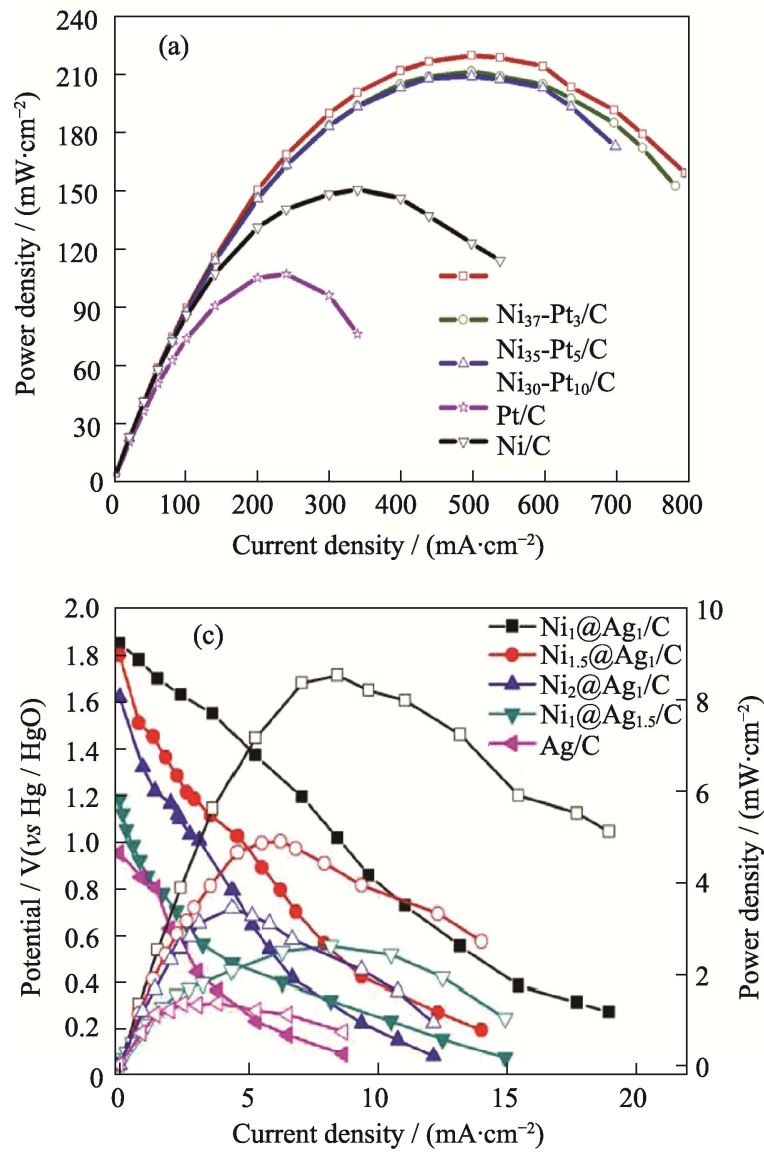
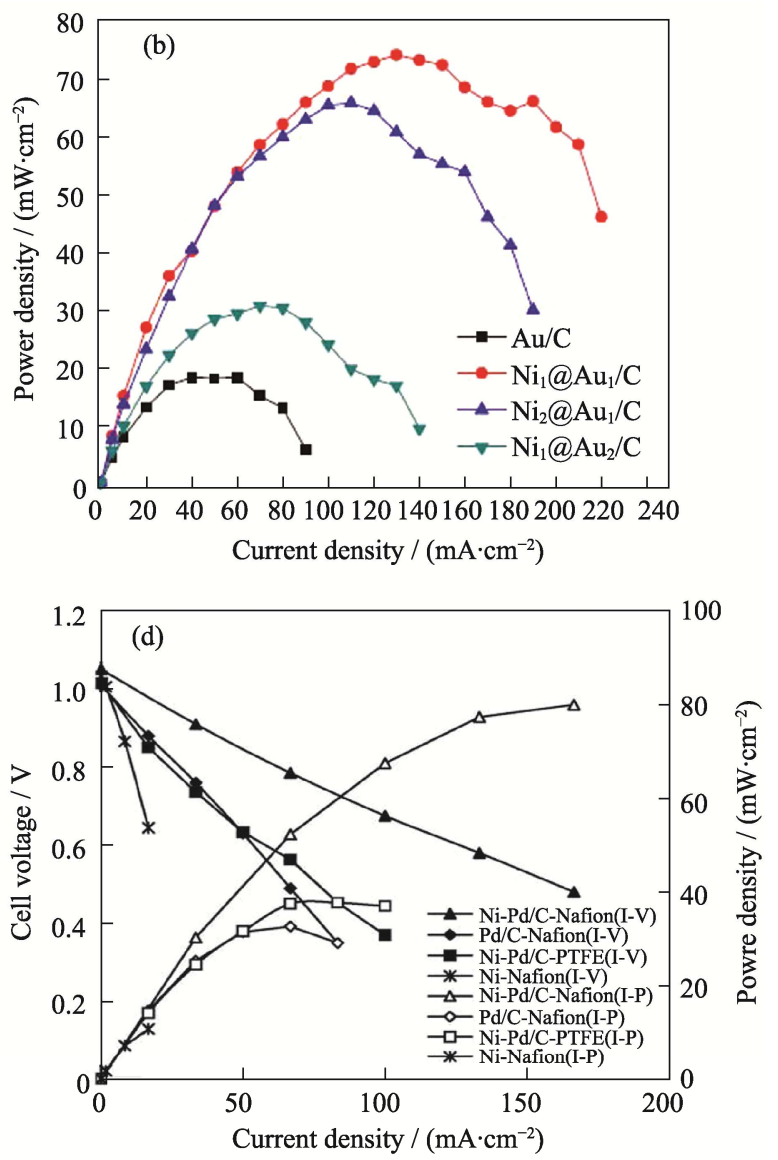

图 3 不同阳极催化剂下 $\mathrm{DBFC}$ 的功率密度曲线 ${ }^{[37-38,40,42]}$

Fig. 3 Power density curves of the DBFC using different anode catalysts ${ }^{[37-38,40,42]}$ (a) $60^{\circ} \mathrm{C}$; (b) $20^{\circ} \mathrm{C}$; (c) $25^{\circ} \mathrm{C}$; (d) $25^{\circ} \mathrm{C}$

的 $\mathrm{Ni}-\mathrm{Co} / \mathrm{C}$ 材料, 与 $\mathrm{Pt} / \mathrm{C}$ 催化剂对比, 该新催化剂 的催化活性明显变高, 但其抗中毒性却变差。此外, $\mathrm{Pd}$ 修饰的 $\mathrm{Ni}-\mathrm{Co} / \mathrm{C}$ 用作阳极催化剂 DBFC 的功率密 度 $\left(126 \mathrm{~mW} / \mathrm{cm}^{2}\right)$ 是 $\mathrm{Pt} / \mathrm{C}$ 作为催化剂 $\left(76 \mathrm{~mW} / \mathrm{cm}^{2}\right)$ 的近 1.7 倍。

在过渡金属中，除了对 $\mathrm{Ni}$ 金属研究较多外，还 对 $\mathrm{Zn} 、 \mathrm{Cu} 、 \mathrm{Fe} 、 \mathrm{Ti} 、 \mathrm{Co}$ 等过渡金属进行了研究, 但 对这些元素的相关性研究还比较少, 而且研究的角 度也不够广。它们作为 DBFC 阳极催化剂时, 主要 是与贵金属结合形成二元金属, 如 $\mathrm{Au}-\mathrm{Zn}^{[47]}$ 、 $\mathrm{Pt}-\mathrm{Zn}^{[48]} 、 \mathrm{Ag}-\mathrm{Cu}^{[49]} 、 \mathrm{Pd}-\mathrm{Cu}^{[50-51]} 、 \mathrm{Au}-\mathrm{Fe}^{[52]}$ 、 $\mathrm{Ag}(\mathrm{Au})-\mathrm{Ti}^{[53]}$ 等。而对金属 $\mathrm{Co}$ 来说, 主要是对合成 的 $\mathrm{Co}-\mathrm{B}^{[54-55]} \mathrm{Au}$ 修饰的 $\mathrm{Co}-\mathrm{B}^{[56]}$ 合金进行了研究。

\section{3 储氢合金催化剂}

近年来，储氢合金(常用于镍氢电池)独特的可 逆吸放氢性能激起了研究者们的兴趣, 人们开始尝 试用储氢合金做 DBFC 阳极催化剂, 相关研究也取 得了一些进展。

与贵金属相比, 储氢合金做 DBFC 阳极催化剂 首先在成本上大幅下降。此外, 储氢合金将氢原子
储存在其合金晶格相中，可减少 DBFC 阳极水解而 放氢，从而提高燃料的利用率。Lee 等 ${ }^{[57]}$ 对嗍氢化 物在 $\mathrm{AB}_{2}$ 型 $\mathrm{ZrCr}_{0.8} \mathrm{Ni}_{1.2}$ 储氢合金上的电氧化性能进 行了研究, 发现储氢合金吸附硼氢化物溶液中的氢, 这种吸附使嗍氢化物中的氢转移到储氢合金上，发 生库仑数接近 $8 \mathrm{e}$ 的电化学氧化反应, 从而提高了嗍 氢化物的利用率。分析认为储氢合金上近 $8 \mathrm{e}$ 是由储 氢合金的特殊性造成的。作为 DBFC 的阳极材料, 储氢合金能在体相中存储氢原子, 从而减少放氢。 具体而言, 在反应过程中, 硼氢化物水解产生的氢 首先存储在储氢合金中, 然后再发生如下的电化学 氧化反应:

$$
\mathrm{MH}_{x}+x \mathrm{OH}^{-}=\mathrm{M}+x \mathrm{H}_{2} \mathrm{O}+x \mathrm{e}^{-}
$$

可见，通过使用储氢合金作为阳极催化剂，可以提高 燃料的利用率。Wang 等 ${ }^{[58]}$ 尝试用 $\mathrm{AB}_{5}$ 型 $\mathrm{LaNi}_{4.5}-\mathrm{Al}_{0.5}$ 储氢合金作为 DBFC 的阳极催化剂, 研究表明正是 由于氢在储氢电极上的吸收和转化, 缓解了水解反 应。文献[4]报道 $\mathrm{AB}_{5}$ 型合金作为 $\mathrm{DBFC}$ 阳极催化剂 能比 $\mathrm{AB}_{2}$ 型合金获得更高的功率密度, 这可能是由 于 $\mathrm{AB}_{5}$ 型合金的储氢能力比 $\mathrm{AB}_{2}$ 型合金强造成的。 
储氢合金对硼氢化物的催化性能与合金的吸放氢性 能有密切的关系。为进一步改善储氢合金的阳极催 化性能，近年来研究者对合金进行了表面修饰、合 金成分优化、合金制备工艺改善等处理。例如，在 $\mathrm{AB}_{5}$ 型合金中掺杂 $\mathrm{Si}$, 燃料利用率由原来的 $20 \%$ 提 高到 $95 \%{ }^{[59]}$ 。用 $\mathrm{Au}$ 修饰的 $\mathrm{LaNi}_{4.5} \mathrm{Al}_{0.5}$ 储氢合金作 为 DBFC 阳极催化剂。发现修饰后合金的催化性能 明显增强, 相应电池的效率增大 ${ }^{[60]}$ 。可见, 储氢合 金改性是改善催化氧化活性、提高 DBFC 效率的一 个有效途径。表 3 总结了近年来使用储氢合金作为 阳极催化剂的 DBFC 的性能参数。

此外, 为了改善储氢合金催化剂的性能, 研究 者们还对储氢合金催化剂进行了修饰, 多数采用非 金属对其进行修饰。例如, 为了提高硼氢化物燃料 的利用率, Gras 等 ${ }^{[61]}$ 采用球磨法用 $\mathrm{Si}$ 和两种碳材料 对 $\mathrm{AB}_{5}$ 型合金进行了修饰。Li 等 ${ }^{[62]}$ 发现 $\mathrm{AB}_{5}$ 型合金 与碳纳米管复合后, 不仅电催化活性得到改善, 电 池的功率密度和稳定性也得到不同程度的改善。王 贵领等 ${ }^{[63]}$ 研究发现 $\mathrm{MnO}_{2}$ 掺杂到 $\mathrm{AB}_{5}$ 型储氢合金催 化剂能有效改善合金的电催化活性, 分析认为这主 要是由于 $\mathrm{MnO}_{2}$ 改善了储氢合金的表面性能, 提高 了储氢合金表面的导电性，进而提高了储氢合金对 嗍氢化钠氧化的电催化活性。可见, 储氢合金和其 他催化剂复合及其协同作用, 是改善储氢合金催化 性能的一种有效途径。
储氢合金是一种极具潜力的非贵金属催化剂, 但目前有关储氢合金作为 DBFC 阳极催化剂的研究 时间不长, 相关研究还比较少。储氢合金的种类很 多, 但目前仅发现利用 $\mathrm{AB}_{5}$ 和 $\mathrm{AB}_{2}$ 型合金做阳极催 化剂(见表 3), 其他储氢合金的相关研究还鲜见报 道。储氢合金作为 DBFC 阳极催化剂时, 可有效解 决硼氢化物的水解问题, 但对硼氢化物的氧化催化 性还不够理想，如何通过对储氢合金改性(例如改 变合金晶体结构、减小合金颗粒尺寸、合金表面修 饰等)提高氧化催化性能, 这是目前急需研究的。此 外, 特别是储氢合金作为 DBFC 阳极催化剂的催化 机理尚不清晰, 也是急需解决的问题。微观结构决 定宏观性能, 要设计和实施新实验方法和步骤以满 足燃料电池应用对催化剂高催化活性、强稳定性和 低成本的要求, 必须掌握催化剂催化活性位的特 征、结构和催化方式, 因此催化机理的探索是至关 重要的。

最后, 值得一提的是, DBFC 阳极催化剂的催化 性能、电池能量密度等与使用条件有密切的关系。 即使是同一催化剂, 采用不同的测试条件, 例如测 试温度、硼氢化物浓度、催化剂的单载量等也会得 到不同的测试结果 ${ }^{[64]}$, 因而给篮选和设计高性能 DBFC 阳极催化剂造成一定的困难。为了客观准确地 评价催化剂, 研究 DBFC 阳极催化剂的测试条件对 其性能的影响也是十分必要的。

表 3 储氢合金作为阳极催化剂的 DBFC 的性能参数

Table 3 Performance data for DBFCs employing hydrogen storage alloy anodes

\begin{tabular}{|c|c|c|c|c|c|}
\hline Anode catalyst & Cathode catalyst & Oxidant & $\mathrm{T} /{ }^{\circ} \mathrm{C}$ & $\begin{array}{l}\text { Power density/ } \\
\left(\mathrm{mW} \cdot \mathrm{cm}^{-2}\right)\end{array}$ & Ref. \\
\hline $\mathrm{LmNi}_{4.78} \mathrm{Mn}_{0.22}$ & Nickel foam & NA & NA & NA & {$[65]$} \\
\hline $\mathrm{MmNi}_{3.55} \mathrm{Al}_{0.3} \mathrm{Mn}_{0.4} \mathrm{Co}_{0.75}$ & FeTMPP/C & $\mathrm{H}_{2} \mathrm{O}_{2}+\mathrm{H}_{2} \mathrm{SO}_{4}$ & 70 & 82 & [66] \\
\hline $\mathrm{MmNi}_{3.55} \mathrm{Al}_{0.3} \mathrm{Mn}_{0.4} \mathrm{Co}_{0.75}$ & $\mathrm{PbSO}_{4} / \mathrm{C}$ & $\mathrm{H}_{2} \mathrm{O}_{2}+\mathrm{H}_{2} \mathrm{SO}_{4}$ & 70 & 120 & [66] \\
\hline $\mathrm{MmNi}_{3.35} \mathrm{Co}_{0.75} \mathrm{Mn}_{0.4} \mathrm{Al}_{0.3}$ & $\mathrm{MnO}_{2} / \mathrm{C}$ & $\mathrm{O}_{2}$ & 25 & 70 & [67] \\
\hline $\mathrm{MmNi}_{3.6} \mathrm{Al}_{0.4} \mathrm{Mn}_{0.3} \mathrm{Co}_{0.7}$ & $\mathrm{Au} / \mathrm{SS}$ mesh & $\mathrm{H}_{2} \mathrm{O}_{2}+\mathrm{H}_{2} \mathrm{SO}_{4}$ & 25 & 50 & [68] \\
\hline $\mathrm{MmNi}_{3.55} \mathrm{Co}_{0.75} \mathrm{Mn}_{0.4} \mathrm{Al}_{0.3}$ & Iron phthalocyanin/C & Air & RT & 92 & [69] \\
\hline $\mathrm{MmNi}_{3.6} \mathrm{Al}_{0.4} \mathrm{Mn}_{0.3} \mathrm{Co}_{0.7}$ & $\mathrm{PbSO}_{4} / \mathrm{C}$ & $\mathrm{H}_{2} \mathrm{O}_{2}+\mathrm{H}_{2} \mathrm{SO}_{4}$ & 25 & 10 & {$[70]$} \\
\hline $\mathrm{MmNi}_{3.55} \mathrm{Co}_{0.75} \mathrm{Mn}_{0.4} \mathrm{Al}_{0.3}$ & Cobalt phthalocyanin & Air & RT & 90 & [71] \\
\hline $\mathrm{MmNi}_{3.55} \mathrm{Co}_{0.75} \mathrm{Mn}_{0.4} \mathrm{Al}_{0.3}$ & Prussian blue & $\mathrm{H}_{2} \mathrm{O}_{2}+\mathrm{H}_{2} \mathrm{SO}_{4}+\mathrm{KCl}$ & 30 & 68 & [72] \\
\hline $\mathrm{MmNi}_{3.55} \mathrm{Co}_{0.75} \mathrm{Mn}_{0.4} \mathrm{Al}_{0.3}$ & $\mathrm{LaNiO}_{3} / \mathrm{C}$ & Air & 65 & 127 & {$[73]$} \\
\hline $\mathrm{La}_{10.5} \mathrm{Ce}_{4.3} \mathrm{Pr}_{0.5} \mathrm{Nd}_{1.4} \mathrm{Ni}_{60.0} \mathrm{Co}_{12.7} \mathrm{Mn}_{5.9} \mathrm{Al}_{4.7}$ & $\mathrm{Pd} / \mathrm{C}$ & Air & NA & 81 & [74] \\
\hline $\mathrm{MmNi}_{3.55} \mathrm{Co}_{0.75} \mathrm{Mn}_{0.4} \mathrm{Al}_{0.3}$ & $\mathrm{LaCoO}_{3} / \mathrm{C} / \mathrm{Ni}$-foam & Air & RT & 65 & [62] \\
\hline $\mathrm{LaMnNi}_{3.55} \mathrm{Al}_{0.30} \mathrm{Mn}_{0.40} \mathrm{Co}_{0.75}$ & Nickel foam & Air & NA & NA & [61] \\
\hline $\mathrm{Zr}_{0.9} \mathrm{Ti}_{0.1} \mathrm{Mn}_{0.6} \mathrm{~V}_{0.2} \mathrm{Co}_{0.1} \mathrm{Ni}_{1.1}$ & $\mathrm{Pt} / \mathrm{C}$ & $\mathrm{O}_{2}$ & 85 & 190 & [75] \\
\hline $\mathrm{Zr}_{0.9} \mathrm{Ti}_{0.1} \mathrm{Mn}_{0.6} \mathrm{~V}_{0.2} \mathrm{Co}_{0.1} \mathrm{Ni}_{1.1}$ & $\mathrm{Pt} / \mathrm{C}$ & $\mathrm{O}_{2}$ & 60 & NA & {$[76]$} \\
\hline $\mathrm{ZrCr}_{0.8} \mathrm{Ni}_{1.2}$ & $\mathrm{Pt} / \mathrm{C}$ & $\mathrm{O}_{2}$ & 25 & NA & [57] \\
\hline $\mathrm{Zr}_{0.9} \mathrm{Ti}_{0.1} \mathrm{~V}_{0.2} \mathrm{Mn}_{0.6} \mathrm{Cr}_{0.05} \mathrm{Co}_{0.05} \mathrm{Ni}_{1.2}$ & $\mathrm{Pt} / \mathrm{C}$ & $\mathrm{H}_{2} \mathrm{O}_{2}$ & 70 & 70 & [77] \\
\hline
\end{tabular}

* NA: Information not available in the cited literature; * RT: Room temperature. 


\section{3 结束语}

近年来，随着低温燃料电池关键技术的突破和 成本的降低，这种没有污染、安全、高效的燃料电 池已进入商业示范阶段。可以预见，在不远的将来， 低温燃料电池将会在国防、工业和民用等领域有着 举足轻重的地位, 成为未来 20 年中世界经济的增长 点。直接硼氢化物燃料电池(DBFC) 比一般燃料电池 具有更高的理论输出电压和功率密度、可用普通催 化剂替代贵金属，可在常温下工作、无毒、运输安全 等优点, 而受到研究者们的极大青睐。但是, DBFC 的性能很大程度上取决于嗍氢化物分子在阳极上发 生的电化学反应, 而阳极上的电化学反应又直接受 阳极催化剂的控制。研究和开发稳定性高、催化活 性好、成本价格低的阳极催化剂对推动 DBFC 产业 化发展具有重要的理论和现实意义。近年来, DBFC 阳极催化剂的研究经历了贵金属、过渡金属、储氢 合金以及它们的复合物等历程，在提高阳极催化剂 的催化活性、稳定性以及降低成本方面取得较明显 的进步。但是, 在各类阳极催化剂研究发展过程中 仍面临很多问题, 还有待进一步深入研究。

（1）目前，作为阳极催化剂的贵金属主要有 Pt、 $\mathrm{Au} 、 \mathrm{Pd} 、 \mathrm{Ag} 、 \mathrm{Os}$, 其他种类贵金属的研究还鲜见报 道。此外, 任何一种贵金属作为阳极催化剂都存在固 有缺点，不同种类贵金属复合可以有效改善催化性 能。贵金属复合时，贵金属种类选取、制备工艺、 组元比例等都值得进一步研究。

（2）相对贵金属，较廉价的过渡金属单质作为 阳极催化剂对 $\mathrm{BH}_{4}{ }^{-}$的催化活性较低, 电子转移数也 不多, 导致电池的库仑效率低, 燃料损失严重。过渡 金属通过与贵金属的复合可以有效改善其催化性能, 提高库仑效率。但过渡金属与贵金属复合形成二元 甚至多元金属催化剂时，金属种类选取、制备工艺、 组元比例等都值得深入研究。

(3) 储氢合金作为阳极催化剂在抑制水解反应 和降低成本上显示出较好的优势，然而该类催化剂 尚处于初期研究阶段，已有研究仅涉及 $A^{\prime} B_{5}$ 和 $A B_{2}$ 型两类储氢合金，其他种类储氢合金还鲜见报道。该 类合金对硼氢化物的氧化催化活性还不够理想，如 何通过对储氢合金改性(例如改变合金晶体结构、减 小合金颗粒尺寸、合金表面修饰等)和复合(与贵金 属、过渡金属、储氢合金等)提高氧化催化活性，这 是目前急需研究的。特别是储氢合金作为阳极催化 剂的催化性能、储氢性能以及它们之间交互影响关 系尚不清楚，催化机理仍需进一步研究。
参考文献:

[1] ROSEN M A, KOOHI-FAYEGH S. The prospects for hydrogen as an energy carrier: an overview of hydrogen energy and hydrogen energy systems. Energy, Ecology and Environment, 2016, 1(1): $10-29$.

[2] SONG M Y, PARK H R, KWON S N. Evaluation of the metal-added Mg hydrogen storage material and comparison with the oxide-added Mg. Journal of Industrial and Engineering Chemistry, 2015, 21: 378-386.

[3] DE LEON C P, WALSH F C, PLETCHER D, et al. Direct borohydride fuel cells. Journal of Power Sources, 2006, 155(2): 172- 181.

[4] MA J, CHOUDHURY N A, SAHAI Y. A comprehensive review of direct borohydride fuel cells. Renewable and Sustainable Energy Reviews, 2010, 14(1): 183-199.

[5] MERINO-JIMENEZ I, DE LEON C P, SHAH A A, et al. Developments in direct borohydride fuel cells and remaining challenges. Journal of Power Sources, 2012, 219: 339-357.

[6] OLU P Y, JOB N, CHATENET M, et al. Evaluation of anode (electro)catalytic materials for the direct borohydride fuel cell: methods and benchmarks. Journal of Power Sources, 2016, 327: 235-257.

[7] YI L H, SONG Y F, YI W, et al. Carbon supported Pt hollow nanospheres as anode catalysts for direct borohydride-hydrogen peroxide fuel cells. International Journal of Hydrogen Energy, 2011, 36(18): 11512-11518.

[8] WEI J L, WANG X Y, WANG Y, et al. Investigation of carbonsupported Au hollow nanospheres as electrocatalyst for electrooxidation of sodium borohydride. International Journal of Hydrogen Energy, 2009, 34(8): 3360-3366.

[9] CHATENET M, MICOUD F, ROCHE I, et al. Kinetics of sodium borohydride direct oxidation and oxygen reduction in sodium hydroxide electrolyte-Part I. $\mathrm{BH}_{4}{ }^{-}$electro-oxidation on $\mathrm{Au}$ and $\mathrm{Ag}$ catalysts. Electrochimica Acta, 2006, 51(25): 5459-5467.

[10] CHENG H, SCOTT K. Determination of kinetic parameters for borohydride oxidation on a rotating Au disk electrode. Electrochimica Acta, 2006, 51(17): 3429-3433.

[11] ATWAN M H, MACDONALD C L B, NORTHWOOD D O, et al. Colloidal $\mathrm{Au}$ and Au-alloy catalysts for direct borohydride fuel cells: electrocatalysis and fuel cell performance. Journal of Power Sources, 2006, 158(1): 36-44.

[12] CELIKKAN H, SAHIN M, AKSU M L, et al. The investigation of the electrooxidation of sodium borohydride on variousmetal electrodes in aqueous basic solutions. International Journal of Hydrogen Energy, 2007, 32(5): 588-593.

[13] PONCE-DE-LEON C, BAVYKIN D V, WALSH F C. The oxidation of borohydride ion at titanate nanotube supported gold electrodes. Electrochemistry Communications, 2006, 8(10): 1655-1660.

[14] CONCHA B M, CHATENET M. Direct oxidation of sodium borohydride on Pt, Ag and alloyed Pt-Ag electrodes in basic media Part II. carbon-supported nanopaticles. Electrochimica Acta, 2009, 54(26): 6130-6139.

[15] LIU B H, LI Z P. A review: hydrogen generation from borohydride hydrolysis reaction. Journal of Power Sources, 2009, 187(2): 527534.

[16] QIN H Y, CHEN K J, ZHU C, et al. High electrocatalytic activity for borohydride oxidation on palladium nanocubes enclosed by $\{200\}$ facets. Journal of Power Sources, 2015, 299: 241-245.

[17] LIU B H, LI Z P, SUDA S. Electrocatalysts for the anodic oxidation of borohydrides. Electrochimica Acta, 2004, 49(19): 30973105. 
[18] GYENGE E, ATWAN M, NORTHWOOD D. Electrocatalysis of borohydride oxidation on colloidal Pt and Pt-alloys (Pt-Ir, Pt-Ni, and Pt-Au) and application fordirect borohydride fuel cell anodes. Journal of the Electrochemical Society, 2006, 153(1): A150-A158.

[19] CHENG H, SCOTT K, LOVELL K. Material aspects of the design and operation of direct borohydride fuel cells. Fuel Cells, 2006, 6(5): $367-375$.

[20] LAM V W S, KANNANGARA D C W, ALFANTAZI A, et al. Electrodeposited osmium three-dimensional anodes for direct borohydride fuel cells. Journal of Power Sources, 2012, 212: 57-65.

[21] LIU J, WANG H, WU C, et al. Preparation and characterization of nanoporous carbon-supported platinum as anode electrocatalyst for direct borohydride fuel cell. International Journal of Hydrogen Energy, 2014, 39(12): 6729-6736.

[22] REZA O, JAHAN-BAKHSH R, ROUDABEH V. Pt nanoparticles/ graphene paste electrode for sodium borohydride electrooxidation. Journal of Solid State Electrochemistry, 2013, 17(1): 217- 221.

[23] MARTINS M, ŠLJUKIĆ B, SEQUEIRA C A C, et al. Biobased carbon-supported palladium electrocatalysts for borohydride fuel cells. International Journal of Hydrogen Energy, 2016, 41(25): 10914-10922.

[24] CHENG K, JIANG J T, KONG S Y, et al. Pd nanoparticles support on rGO-C@TiC coaxial nanowires as a novel 3D electrode for $\mathrm{NaBH}_{4}$ electrooxidation. International Journal of Hydrogen Energy, 2017, 42(5): 2943-2951.

[25] COOWAR F A, VITINS G, MEPSTED G O, et al. Electrochemical oxidation of borohydride at nano-gold-based electrodes: application in direct borohydride fuel cells. Journal of Power Sources, 2008, 175(1): 317-324.

[26] KARADAG C I, BEHMENYAR G, BOYACI SAN F, et al. Investigation of carbon supported nanostructured PtAu alloy as electrocatalyst for direct borohydride fuel cell. Fuel Cells, 2015, 15(2): 262-269.

[27] LEE H M, PARK S Y, PARK K T, et al. Development of Au-Pd catalysts supported on carbon for a direct borohydride fuel cell. Research on Chemical Intermediates, 2008, 34(8/9): 787-792.

[28] LAM V W S, ALFANTAZI A, GYENGE E L. The effect of catalyst support on the performance of PtRu in direct borohydride fuel cell anodes. Journal of Applied Electrochemistry, 2009, 39(10): $1763-1770$.

[29] MERINO-JIMENEZ I, JANIK M J, DE LEON C P, et al. Pd-Ir alloy as an anode material for borohydride oxidation. Journal of Power Sources, 2014, 269: 498-508.

[30] WANG H, WANG X Y, HE P Y, et al. Performance of AuPd/C as anode catalyst of direct $\mathrm{NaBH}_{4}-\mathrm{H}_{2} \mathrm{O}_{2}$ fuel cell. The Chinese Journal of Nonferrous Metals, 2011, 21(2): 405-410.

[31] LI J, QIAN G C, ZHU Y X, et al. Electrochemical behaviour of $\mathrm{Pd}-\mathrm{Ag} / \mathrm{C}$ towards sodium borohydride electrooxidation. Chemical Industry and Engineering, 2016, 33(5): 45-49.

[32] BALCIUNAITE A, SUKACKIENE Z, TAMASAUSKAITETAMASIUNAITE L, et al. $\mathrm{CoB} / \mathrm{Cu}$ and $\mathrm{PtCoB} / \mathrm{Cu}$ catalysts for borohydride fuel cells. Electrochimica Acta, 2017, 225: 255-262.

[33] LIU B H, LI Z P, SUDA S. Anodic oxidation of alkali borohydrides catalyzed by nickel. Journal of the Electrochemical Society, 2003, 150(3): A398-A402.

[34] LIU B H, LI Z P, ARAI K, et al. Performance improvement of a micro borohydride fuel cell operating at ambient conditions. Electrochimica Acta, 2005, 50(18): 3719-3725.

[35] MALYALA R V, RODE C V, ARAI M, et al. Activity, selectivity and stability of $\mathrm{Ni}$ and bimetallic $\mathrm{Ni}-\mathrm{Pt}$ supported on zeolite $\mathrm{Y}$ catalysts for hydrogenation of acetophenone and its substituted derivatives. Applied Catalysis A General, 2000, 193(1/2): 71-86.
[36] JAMARD R, LATOUR A, SALOMON J, et al. Study of fuel efficiency in a direct borohydride fuel cell. Journal of Power Sources, 2008, 176(1): 287-292.

[37] GENG X Y, ZHANG H M, YE W, et al. Ni-Pt/C as anode electrocatalyst for a direct borohydride fuel cell. Journal of Power Sources, 2008, 185(2): 627-632.

[38] DUAN D H, LIANG J W, LIU H H, et al. The effective carbon supported coreeshell structure of $\mathrm{Ni@Au} \mathrm{catalysts} \mathrm{for} \mathrm{electro-}$ oxidation of borohydride. International Journal of Hydrogen Energy, 2015, 40(1): 488-500.

[39] LIANG J W, LIU H H, WEI H K, et al. Studies of anode of sodium borohydride fuel cell. Chinese Journal of Power Sources, 2015, 39(10): 2119-2122.

[40] DUAN D H, WANG Q, LIU H H, et al. Investigation of carbonsupported Ni@Ag core-shell nanoparticles as electrocatalyst for electrooxidation of sodium borohydride. Journal of Solid State Electrochemistry, 2016, 20(10): 2699-2711.

[41] FENG R X, CAO Y L, AI X P, et al. AgNi alloy used as anodic catalyst for direct borohydride fuel cells. Acta Physico-Chimica Sinica, 2007, 23(6): 932-934.

[42] LIU B H, LI Z P, SUDA S. Development of high-performance planar borohydride fuel cell modules for portable applications. Journal of Power Sources, 2008, 175(1): 226-231.

[43] SANTOS D M F, SLJUKIC B, AMARAL L, et al. Nickel and nickel-cerium alloy anodes for direct borohydride fuel cells. Journal of the Electrochemical society, 2014, 161(5): F594-F599.

[44] SANTOS D M F, SLJUKIC B, AMARAL L, et al. Nickel-rare earth electrodes for sodium borohydride electrooxidation. Electrochimica Acta, 2016, 190: 1050-1056.

[45] YU D M, SHEN Y, YE Z, et al. The preparation and performance of high activity Ni-Cr binary catalysts for direct borohydride fuel cells. Chinese Science Bulletin, 2013, 58(20): 2435-2439.

[46] ZHIANI M, MOHAMMADI I. Performance study of passive and active direct borohydride fuel cell employing a commercial Pd decorated Ni-Co/C anode catalyst. Fuel, 2016, 166: 517-525.

[47] HE P Y, WANG X Y, FU P, et al. The studies of performance of the $\mathrm{Au}$ electrode modified by $\mathrm{Zn}$ as the anode electrocatalyst of direct borohydride fuel cell. International Journal of Hydrogen Energy, 2011, 36(15): 8857-8863.

[48] YI L H, WEI W, ZHAO C X, et al. Electrochemical oxidation of sodium borohydride on carbon supported Pt-Zn nanoparticle bimetallic catalyst and its implications to direct borohydride-hydrogen peroxide fuel cell. Electrochimica Acta, 2015, 158: 209-218.

[49] DUAN D H, LIU H H, WANG Q, et al. Kinetics of sodium borohydride direct oxidation on carbon supported $\mathrm{Cu}-\mathrm{Ag}$ bimetallic nanocatalysts. Electrochimica Acta, 2016, 198: 212-219.

[50] BEHMENYAR G, AKIN A N. Investigation of carbon supported $\mathrm{Pd}-\mathrm{Cu}$ nanoparticles as anode catalysts for direct borohydride fuel cell. Journal of Power Sources, 2014, 249: 239-246.

[51] DUAN D H, YOU X, LIANG J W, et al. Carbon supported Cu-Pd nanoparticles as anode catalyst for direct borohydride-hydrogen peroxide fuel cells. Electrochimica Acta, 2015, 176: 1126-1135.

[52] YI L H, WEI W, ZHAO C X, et al. Enhanced activity of Au-Fe/C anodic electrocatalyst for direct borohydride-hydrogen peroxide fuel cell. Journal of Power Sources, 2015, 285: 325-333.

[53] CHENG H, SCOTT K. Investigation of Ti mesh-supported anodes for direct borohydride fuel cells. Journal of Applied Electrochemistry, 2006, 36(12): 1361-1366.

[54] LI S, YANG X D, ZHU H Y, et al. Investigation of amorphous $\mathrm{CoB}$ alloy as the anode catalyst for a direct borohydride fuel cell. Journal of Power Sources, 2011, 196(14): 5858-5862.

[55] LI S, CHEN Y Z, YANG X D, et al. Amorphous metal borides 
used as anode catalyst for DBFC. Battery Bimonthly, 2013, 43(6): 325-328.

[56] LI S, WANG L N, CHU J, et al. Investigation of Au@Co-B nanoparticles as anode catalyst for direct borohydride fuel cells. International Journal of Hydrogen Energy, 2016, 41(20): 8583- 8588.

[57] LEE S M, KIM J H, LEE H, et al. The characterization of an alkaline fuel cell that uses hydrogen storage alloys. Journal of the Electrochemical Society, 2002, 149(5): A603-A606.

[58] WANG L B, MA C A, MAO X B, et al. Rare earth hydrogen storage alloy used in borohydride fuel cells. Electrochemistry Communications, 2005, 7(12): 1477-1481.

[59] WANG L B, MA C A, MAO X B. $\mathrm{LmNi}_{4.78} \mathrm{Mn}_{0.22}$ alloy modified with $\mathrm{Si}$ used as anodic materials in borohydride fuel cells. Journal of Alloys and Compounds, 2005, 397(1/2): 313-316.

[60] YANG Z Z, WANG L B, GAO Y F, et al. $\mathrm{LaNi}_{4.5} \mathrm{Al}_{0.5}$ alloy doped with Au used as anodic materials in a borohydride fuel cell. Journal of Power Sources, 2008, 184(1): 260-264.

[61] GRAS M, SIERCZYNSKA A, LOTA K, et al. The modification of anode material for direct borohydride fuel cell. Ionics, 2016, 22(12): 2539-2544.

[62] LI S, YANG X D, ZHU H Y, et al. Hydrogen storage alloy and carbon nanotubes mixed catalyst in a direct borohydride fuel cell. Journal of Materials Science \& Technology, 2011, 27(12): 10891093.

[63] WANG G L, CHENG Y H, ZHANG W C, et al. Electrocatalytic performances of $\mathrm{MmNi}_{3.2} \mathrm{Al}_{0.2} \mathrm{Mn}_{0.6} \mathrm{Co}_{1.0}$ modified with $\mathrm{MnO}_{2}$ for $\mathrm{NaBH}_{4}$ oxidation. Chemical Journal of Chinese Universities, 2010, 31(1): 153-156.

[64] SAN F G B, KARADAG C L, OKUR O, et al. Optimization of the catalyst loading for the direct borohydride fuel cell. Energy, 2016, 114: $214-224$.

[65] WANG L B, MA C N, SUN Y M, et al. AB 5 -type hydrogen storage alloy used as anodic materials in borohydride fuel cell. Journal of Alloys Compounds, 2005, 391(1/2): 318-322.

[66] RAMAN R K, SHUKLA A K. Electro-reduction of hydrogen peroxide on iron tetramethoxy phenyl porphyrin and lead sulfate elec- trodes with application in direct borohydride fuel cells. Journal of Applied Electrochemistry, 2005, 35(11): 1157-1161.

[67] WANG Y G, XIA Y Y. A direct borohydride fuel cell using $\mathrm{MnO}_{2}$ catalyzed cathode and hydrogen storage alloy anode. Electrochemistry Communications, 2006, 8(11): 1775-1778.

[68] RAMAN R K, PRASHANT S K, SHUKLA A K. A 28-W portable direct borohydride-hydrogen peroxide fuel-cell stack. Journal of Power Sources, 2006, 162(2): 1073-1076.

[69] MA J F, WANG J, LIU Y N. Iron phthalocyanine as a cathode catalyst for a direct borohydride fuel cell. Journal of Power Sources, 2007, 172(1): 220-224.

[70] RAMAN R K, SHUKLA A K. A direct borohydride/hydrogen peroxide fuel cell with reduced alkali crossover. Fuel Cells, 2007, 7(3): 225-231.

[71] MA J F, LIU Y N, ZHANG P, et al. A simple direct borohydride fuel cell with a cobalt phthalocyanine catalyzed cathode. Electrochemistry Communications, 2008, 10(1): 100-102.

[72] SELVARANI G, PRASHANT S K, SAHU A K, et al. A direct borohydride fuel cell employing Prussian Blue as mediated electrontransfer hydrogen peroxide reduction catalyst. Journal of Power Sources, 2008, 178(1): 86-91.

[73] MA J, LIU Y, LIU Y, et al. A membraneless direct borohydride fuel cell using $\mathrm{LaNiO}_{3}$-catalysed cathode. Fuel Cells, 2008, 8(6): 394 398.

[74] CHOUDHURY N A, SAHAI Y, BUCHHEIT R G. Chitosan chemical hydrogel electrode binder for direct borohydride fuel cells. Electrochemistry Communications, 2011, 13(1): 1-4.

[75] LI Z P, LIU B H, ARAI K, et al. A fuel cell development for using borohydrides as the fuel. Journal of the Electrochemical Society, 2003, 150(7): A868-A872.

[76] LI Z P, LIU B H, ARAI K, et al. Evaluation of alkaline borohydride solutions as the fuel for fuel cell. Journal of Power Sources, 2004, 126(1/2): 28-33.

[77] CHOUDHURY N A, RAMAN R K, SAMPATH S, et al. An alkaline direct borohydride fuel cell with hydrogen peroxide as oxidant. Journal of Power Sources, 2005, 143(1/2): 1-8. 